\title{
A power quality enhanced for the wind turbine with sensorless direct power control under different input voltage conditions
}

\begin{abstract}
Introduction. The quality of electrical energy is essential during disturbances, at the level of power electronic devices will suffer serious operating problems causing dangerous damage. Aim. A new approach to direct power control without grid voltage sensor improves the quality and control of instantaneous active and reactive power converters. Methodology. First, the technique without network voltage sensor with a direct power control based on a switching table, which is a classic approach, is discussed and its performance is analyzed under increasing and decreasing load. In addition, the performance of the proposed technique is also analyzed under the same circumstances and their performance is compared. Originality. The new method consists of a nonlinear grid voltage modulated controller and a conventional controller which guarantees very good results in a polluted network. The proposed method is verified using MATLAB/Simulink. Results. The simulation results under different input voltage conditions show that the proposed method not only has good tracking performance in active and reactive power, but also reduces the current total harmonic distortion to $1.9 \%$, which is good lower than the requirement for network operation. References 17, tables 2 , figures 11 . Key words: direct power control, virtual flux, grid voltage modulated, constant switching frequency.
\end{abstract}

Вступ. Якість електроенергї має важливе значення під час збоїв, на рівні силових електронних пристроїв будуть мати місие серйозні проблеми експлуатаиії, що викликають небезпечні пошкодження. Мета. Новий підхід до прямого керування потужністю без датчика напруги мережі покращує якість та контроль перетворювачів миттєвої активної та реактивноі потужності. Методологія. Спочатку обговорюється методика без датчика напруги мережі з прямим керуванням потужністю на основі таблииі перемикання, щзо є класичним підходом, та аналізується його продуктивність при збільшенні та зменшенні навантаження. Крім того, ефективність запропонованої методики також аналізується за тих же обставин, $і$ їхня продуктивність порівнюється. Оригінальність. Новий метод складається з нелінійного мережевого контролера з модуляиією напруги і звичайного контролера, який гарантує дуже хоромі результати в забрудненій мережі. Запропонований метод перевірясться за допомогою MATLAB/Simulink. Результати. Результати моделювання за різних умов вхідної напруги показують, що запропонований метод не тільки має хороші характеристики відстеження активної та реактивної потужності, але також знижує поточний THD до 1,9\%, що значно нижче, ніж вимоги для роботи мережі.. Бібл. 17, табл. 2, рис. 11.

Ключові слова: пряме керування потужністю, віртуальний потік, модуляція напруги мережі, постійна частота перемикання.

1. Introduction. Grid-connected converters are widely used in the application of smart grids, Flexible Alternating Current Transmission Systems (FACTS) and renewable energy sources (e.g., wind and solar) and various control methods have been investigated so that converters improve their performance [1].

Many studies have focused on the advanced control of the functioning of renewable energies that have been proposed with the same main objective which is the power quality which focuses on an almost sinusoidal input current waveform with a higher power factor and regardless of the input condition whether balanced or distorted but their different principles.

The instantaneous power theory proposed by Japanese researchers [2] is inspired by the Direct Torque Control (DTC) proposed for asynchronous motors [3]. The Direct Power Control (DPC) strategy has received a lot of attention from researchers in recent years due to its many benefits. They have shown that the use of DPC in various converters and applications whether it be matrix [4] or Voltage Source Converter (VSC) at two and three levels based on Fuzzy-Q-Learning algorithm is applied [5] or on active filters [6] is more advantageous.

A DPC switching table has been formulated in which the appropriate switching states are selected from a predefined optimal switching table based on the digitized signals of the instantaneous errors between the commanded and estimated values of active and reactive power extracted by a hysteresis controller and the angular position of the voltage at the terminals of the converter thus guarantees a decoupled control of the powers and good dynamic performance [7].
However, the varying switching frequency results in broadband harmonic spectra, which complicates the design of line filters. To solve the downshift associated with variable frequency operation, various DPC algorithms have been developed for constant switching frequency. One can find various publications studies on how to fix the switching frequency of the DPC. The authors [8] suggest to associate the principle of the DPC with a vector modulation Space Vector Modulation (SVM) in order to obtain a switching frequency constant without the use of a switching table. Other authors [9] combine other technique with DPC to improve the result even more by using Sliding-Mode Control (SMC) it allows to obtain a stabilization response faster than that of the PI controller and a greater robustness. Backstepping improves transient performance [10]. The SVM modulation based on a predictive controller was developed in [11] and even the new method proposed by [12], called Multiple Switching Tables (MST-DPC), performs a real-time selection of the most suitable switching table among four alternatives depending on the operating conditions of the device.

The performance of conventional DPC under unbalanced and/or distorted input voltages deteriorates when this occurs. In recent years, researchers are increasingly interested in control methods to improve the performance of DPC strategies under unbalanced grid voltage conditions. Most solutions to improve the performance of three-phase Pulse Width Modulation (PWM) rectifiers are based on the extraction of the

(c) Z.E.Z. Laggoun, H. Benalla, K. Nebti 
positive/negative voltage/current sequences. These solutions are complicated and difficult to implement for real-time applications since they require a great deal of computation.

In Virtual Flux-based (VF) methods, the VF space vector is obtained by integrating the voltage space vector. The use of a pure integrator induces a shift of the direct current in the estimated VF in order to remedy this drawback. Several methods of practical implementation of VF estimation have been proposed, with the aim of avoiding saturation of the estimated signals. This integration is generally performed via a First Order Low Pass (FLOP) filter to avoid the saturation and DC drift problems associated with pure integrators [13]. The DPC Control Based Virtual Flux (VF-DPC) uses the detected $\mathrm{AC}$ line currents and the estimated VF to calculate the input powers. However, FLOP filters lead to amplitude and phase errors. Although these errors can be minimized by reducing the cut-off frequency of the filter, this reduction leads to a reduction in the passband of the filter and therefore to a degradation of its dynamics. And for that, the authors $[14,15]$ propose a second order generalized integrator (SOGI) estimator exploiting the concept of virtual flow. Recent research in [16] presents a combination of two cascade filters to achieve a VF-based timing scheme, to ensure that the gate currents emulate the desirable sine waveform even when the supply voltage is unbalanced and/or harmonized.

Although the Grid Voltage Modulated Direct Power Control (GVM-DPC) is first introduced in [17], the main contribution of this paper is the proposal for an improvement in the technique using VF incorporated in a DPC scheme (GVM-DPC), for a three-phase PWM rectifier in our case. The results of the simulation of VFGVM-DPC are compared with GVM-DPC under a polluted network which gives better performance than the classical method. The VF algorithm has an open loop structure and uses the fundamental orthogonal output signals which are obtained directly from the estimation of the fundamental active and reactive powers. This method provides quasi-sinusoidal input current waveform under different input voltage condition and achieves good stability, improves the performance of GVM-DPC.

The goal of the paper is the mathematical analysis and the numerical implementation of an improved method of grid voltage modulated based on direct power control for three phase pulse width modulation rectifiers.

The rest of the paper is organized as follows. In Section 2 the system modeling and the design of the GVM-DPC controls are presented. Section 3 shows the simulation results using MATLAB/Simulink. Finally, conclusions are given in the last Section 4.

\section{Virtual flux grid voltage modulated direct power control.}

\subsection{Modeling VSC.}

Figure 1 shows a simplified circuit of a two-level VSC connected to the grid with an LR filter all of these are considered ideal switches. The DC side could be connected to renewable energy sources or energy storage systems with a capacitor $\mathrm{C}$ and even at transmission scale High Voltage DC.

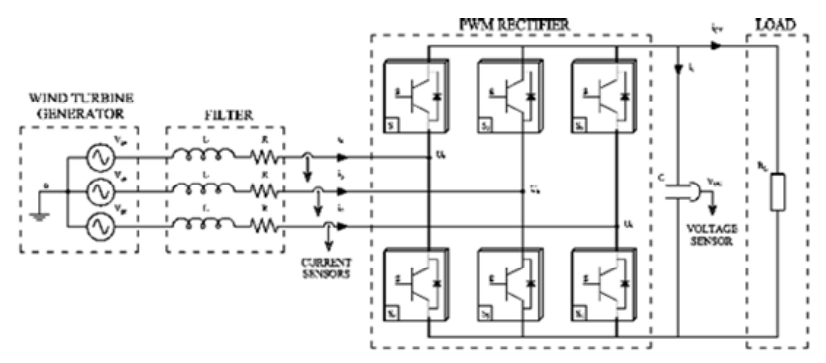

Fig. 1. Representation of a VSC connected to wind turbine generator

The relationship among the VSC output voltages, the grid voltages, and the output currents in the stationary reference frame by using the Clark transformation can be expressed as:

$$
\left\{\begin{array}{l}
U_{\alpha}=R \cdot i_{\alpha}+L \cdot \frac{\mathrm{d} i_{\alpha}}{\mathrm{d} t}+V_{g \alpha} \\
U_{\beta}=R \cdot i_{\beta}+L \cdot \frac{\mathrm{d} i_{\beta}}{\mathrm{d} t}+V_{g \beta},
\end{array}\right.
$$

where $U_{\alpha}$ and $U_{\beta}$ indicate the VSC output voltage; $i_{\alpha}$ and $i_{\beta}$ indicate the output currents; $V_{g \alpha}$ and $V_{g \beta}$ indicate the grid voltage in $\alpha \beta$ frame, and $L$ and $R$ are the filter inductance and resistance, respectively.

\subsection{Modeling VF.}

The concept of VF is based on the voltage integral and can be applied as an estimation method for voltagesensor-less control of VSCs:

$$
\Psi_{\alpha \beta}=\int U_{\alpha \beta} \mathrm{d} t=\int\left(R \cdot i_{\alpha \beta}+L \cdot \frac{\mathrm{d} i_{\alpha \beta}}{\mathrm{d} t}+V_{g \alpha \beta}\right) \mathrm{d} t,
$$

where $\Psi_{\alpha \beta}$ is the estimated VF.

The use of the proposed Dual Virtual Flux Phase Locked Loop (DVF-PLL), based on the cascade of two adaptive filters illustrated in Fig. 2, is an optimized solution.

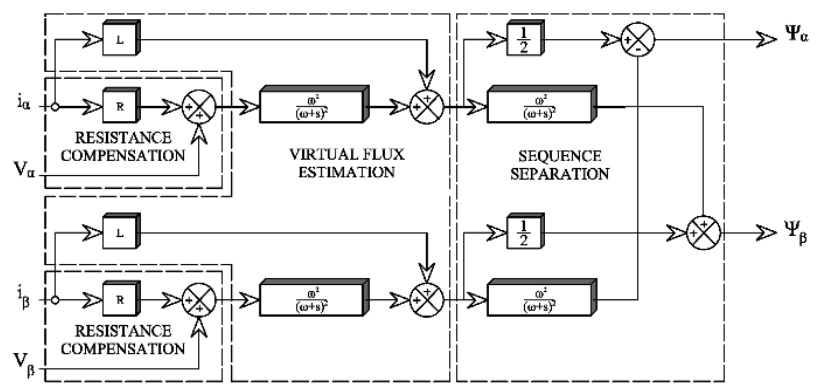

Fig. 2. The diagram of the proposed Dual Virtual Flux estimator

The DVF-PLL filter function is based on the estimated voltage and measurements current. First, the voltage reference signals are expressed in the stationary reference frame $(\alpha \beta)$. Then the resistive voltage drop included in the model is subtracted. The latter is shifted in phase $\left(90^{\circ}\right)$ and gains unity for the fundamental frequency used to estimate the VF components with the secondorder-low-pass filters. The estimated components of the VF are separated in positive and negative sequences with the same transfer function as that used for the estimation of the VF components. By using the estimated VF components in the stationary reference frame, the flux angles can be estimated by using a conventional PLL. The cutoff frequency is equal to $50 \mathrm{~Hz}$ and only the positive 
sequence is used to ensure adequate operation under faulty network conditions [16].

2.3 Fuzzy Controller for PLL. To have good PLL control performance, especially in case of voltage disturbance variation and load disturbance the PI controller will be replaced by a fuzzy controller. The schematic diagram of this control is given in Fig. 3.

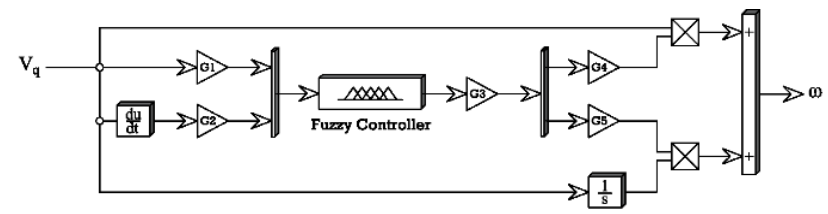

Fig. 3. The PLL fuzzy control

The fuzzy regulator uses two inputs. He first input is the error between the reference and the measured value of the quadratic voltage $V_{q}$. The second one represents the variation of this error.
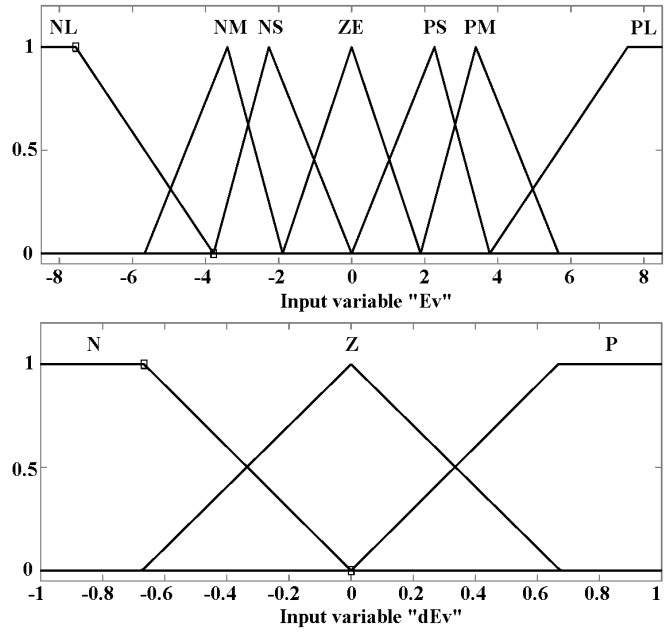

These two signals are expressed by:

$$
\left\{\begin{array}{l}
e=V_{\text {qref }}(n)-V_{q}(n) ; \\
\Delta e=e(n)-e(n-1),
\end{array}\right.
$$

where $e$ and $\Delta e$ are the error of the quadratic voltage and its variation of the error.

For fuzzification, we used triangular membership functions for the error. We chose the seven fuzzy sets: NL (negative large), NM (negative middle), NS (negative small), ZE (zero), PS (positive small), PM (positive middle), PL (positive large). The rate of change $\Delta E \omega$ includes 3 fuzzy subsets, it is not necessary to subdivide it, because it is changing quickly in DPC. Output membership KP and KI, both contain four fuzzy subsets as shown in Fig. 4. There are total of 21 rules as listed in Table 1.
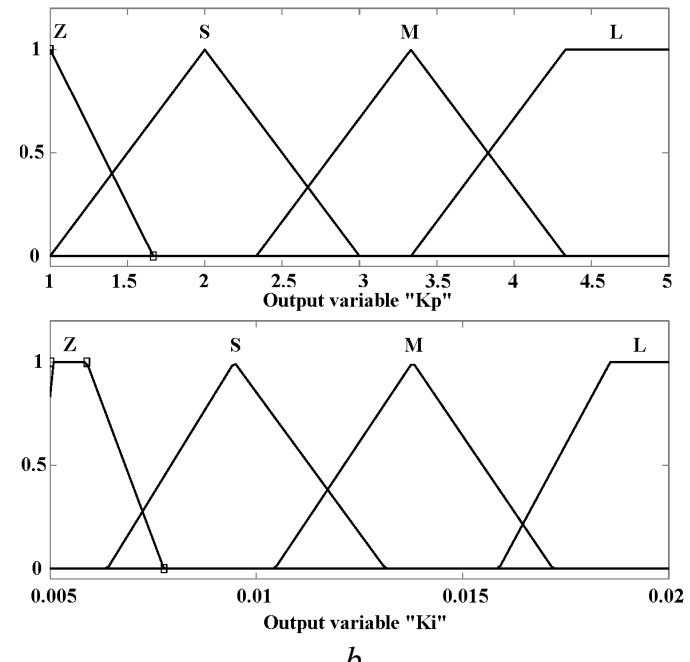

$b$

Fig. 4. The fuzzy membership functions of input $(a)$ and output $(b)$ variables

Table 1

Fuzzy rules

\begin{tabular}{|c|c|c|c|c|c|c|c|c|}
\hline \multirow{2}{*}{\multicolumn{2}{|c|}{$\mathrm{KP}$}} & \multicolumn{7}{|c|}{$E \omega$} \\
\hline & & NL & NM & NS & ZE & PS & PM & PL \\
\hline \multirow{2}{*}{$\Delta \mathrm{E}$} & \multirow{2}{*}{$\mathrm{N}$} & $\mathrm{L}$ & $\mathrm{M}$ & $\mathrm{S}$ & $\mathrm{M}$ & $\mathrm{S}$ & $\mathrm{M}$ & $\mathrm{L}$ \\
\hline & & $Z$ & $\mathrm{~S}$ & $M$ & $\mathrm{~L}$ & $\mathrm{M}$ & $\mathrm{S}$ & Z \\
\hline \multirow{2}{*}{$\Delta \mathrm{E}$} & \multirow{2}{*}{ Z } & $\mathrm{L}$ & $\mathrm{M}$ & $\mathrm{L}$ & $\mathrm{Z}$ & $\mathrm{L}$ & $\mathrm{M}$ & $\mathrm{L}$ \\
\hline & & $Z$ & $\mathrm{~S}$ & $\mathrm{M}$ & $\mathrm{L}$ & $\mathrm{M}$ & $\mathrm{S}$ & $\mathrm{Z}$ \\
\hline \multirow{2}{*}{$\Delta \mathrm{E}$} & \multirow{2}{*}{$P$} & $\mathrm{~L}$ & $\mathrm{M}$ & $\mathrm{L}$ & $\mathrm{Z}$ & $\mathrm{L}$ & $\mathrm{M}$ & $\mathrm{L}$ \\
\hline & & Z & $\mathrm{M}$ & $\mathrm{L}$ & $\mathrm{L}$ & $\mathrm{L}$ & $\mathrm{M}$ & Z \\
\hline
\end{tabular}

2.4 Modeling DPC. Line current and VF components are used in power calculations. It should be noted that electrical resistance is included in the estimation process VF, they can be calculated by the following expressions:

$$
\left\{\begin{array}{l}
P=\omega \cdot\left(\Psi_{\alpha} \cdot i_{\beta}-\Psi_{\beta} \cdot i_{\alpha}\right) \\
Q=\omega \cdot\left(\Psi_{\alpha} \cdot i_{\alpha}+\Psi_{\beta} \cdot i_{\beta}\right)
\end{array}\right.
$$

where $P$ is the estimate active power; $Q$ is the estimate reactive power; $\omega$ is the angular frequency of the grid fundamental wave; $\Psi_{\alpha}, \Psi_{\beta}, i_{\alpha}, i_{\beta}$ are respectively the virtual flow and the currents in the reference $\alpha \beta$.

By deriving (3) with respect to time, instantaneous variations in active and reactive power $\mathrm{d} P / \mathrm{d} t$ and $\mathrm{d} Q / \mathrm{d} t$ respectively can be expressed as a function of variations in network voltage and output current as follows:

$$
\left\{\begin{array}{l}
\frac{\mathrm{d} P}{\mathrm{~d} t}=i_{\beta} \cdot \frac{\mathrm{d} \Psi_{\alpha}}{\mathrm{d} t}+\Psi_{\alpha} \cdot \frac{\mathrm{d} i_{\beta}}{\mathrm{d} t}-i_{\alpha} \cdot \frac{\mathrm{d} \Psi_{\beta}}{\mathrm{d} t}-\Psi_{\beta} \cdot \frac{\mathrm{d} i_{\alpha}}{\mathrm{d} t} \\
\frac{\mathrm{d} Q}{\mathrm{~d} t}=i_{\alpha} \cdot \frac{\mathrm{d} \Psi_{\alpha}}{\mathrm{d} t}+\Psi_{\alpha} \cdot \frac{\mathrm{d} i_{\beta}}{\mathrm{d} t}+i_{\beta} \cdot \frac{\mathrm{d} \Psi_{\beta}}{\mathrm{d} t}-\Psi_{\beta} \cdot \frac{\mathrm{d} i_{\beta}}{\mathrm{d} t} .
\end{array}\right.
$$

If we consider a non-distorted grid, the following relationship could be obtained

$$
\left\{\begin{array}{l}
\frac{\mathrm{d} \Psi_{\alpha}}{\mathrm{d} t}=-\omega \cdot \Psi_{\beta} \\
\frac{\mathrm{d} \Psi_{\beta}}{\mathrm{d} t}=\omega \cdot \Psi_{\alpha}
\end{array}\right.
$$

where $\omega=2 \cdot \pi \cdot f$ is the angular frequency of the grid voltage and $f$ is the frequency of the grid voltage.

By substituting (4) in (5), the state-space model of the active and reactive powers is obtained as follows:

$$
\left\{\begin{array}{l}
\frac{\mathrm{d} P}{\mathrm{~d} t}=-\frac{R}{L} \cdot P-\omega \cdot Q+\frac{1}{L} \cdot\left(\omega \cdot\left(\Psi_{\alpha} \cdot U_{\beta}+\Psi_{\beta} \cdot U_{\alpha}\right)-\Psi_{g}^{2}\right), \\
\frac{\mathrm{d} Q}{\mathrm{~d} t}=\omega \cdot P-\frac{R}{L} \cdot Q+\frac{\omega}{L} \cdot\left(\Psi_{\alpha} \cdot U_{\beta}+\Psi_{\beta} \cdot U_{\alpha}\right),
\end{array}\right.
$$


where

$$
\Psi_{g}^{2}=\omega^{2} \cdot\left(\Psi_{\alpha}^{2}+\Psi_{\beta}^{2}\right)
$$

2.5 Grid voltage modulated direct power control. As mentioned in point (6), our main idea is to decouple the outputs from the inputs. The definition of the control inputs of the GVM is given as follows:

$$
\left\{\begin{array}{l}
v_{P}=\omega \cdot\left(\Psi_{\alpha} \cdot U_{\beta}-\Psi_{\beta} \cdot U_{\alpha}\right), \\
v_{Q}=\omega \cdot\left(\Psi_{\alpha} \cdot U_{\alpha}+\Psi_{\beta} \cdot U_{\beta}\right) .
\end{array}\right.
$$

The space-state model of the active and reactive powers becomes again as follows:

$$
\left\{\begin{array}{l}
\frac{\mathrm{d} P}{\mathrm{~d} t}=-\frac{R}{L} \cdot P-\omega \cdot Q+\frac{1}{L} \cdot\left(v_{P}-\Psi_{g}^{2}\right) \\
\frac{\mathrm{d} Q}{\mathrm{~d} t}=\omega \cdot P-\frac{R}{L} \cdot Q+\frac{1}{L} \cdot v_{Q} .
\end{array}\right.
$$

A controller is designed to let the active and reactive powers track their references. Define errors of the active and reactive powers as follows:

$$
\left\{\begin{array}{l}
e_{P}=P_{r e f}-P \\
e_{Q}=Q_{r e f}-Q,
\end{array}\right.
$$

where $P_{\text {ref }}$ and $Q_{\text {ref }}$ are the active and reactive power references, respectively.

$$
\left\{\begin{array}{l}
U_{P}=\underbrace{\Psi_{g}^{2}+R \cdot P+L \cdot \omega \cdot Q}_{\text {Feedforward }}+\underbrace{L \cdot v_{P}}_{\text {Feedback }} ; \\
U_{Q}=\underbrace{-\omega \cdot L \cdot P+R \cdot Q}_{\text {Feedforward }}+\underbrace{L \cdot v_{Q}}_{\text {Feedback }},
\end{array}\right.
$$

where $U_{P}$ and $U_{Q}$ are the new control inputs; $v_{P}$ and $v_{Q}$ are the feedback control inputs. follows:

If the feedback control inputs are designed as

$$
\left\{\begin{array}{l}
\epsilon_{P}=\dot{P}_{r e f}+K_{P} \cdot e_{P}+K_{P} \cdot \int_{0}^{t} \dot{e}_{P}(t) \mathrm{d} t+K_{P} \cdot \operatorname{sgn}\left(e_{P}\right) ; \\
\epsilon_{Q}=\dot{Q}_{r e f}+K_{Q} \cdot e_{Q}+K_{Q} \cdot \int_{0}^{t} \dot{e}_{Q}(t) \mathrm{d} t+K_{Q} \cdot \operatorname{sgn}\left(e_{Q}\right),
\end{array}\right.
$$

where $t_{P}$ and $t_{Q}$ are the new control inputs; $K_{P}$ and $K_{Q}$ are controller gains.

If we consider a non-distorted grid, the following relationship could be obtained

$$
\left[\begin{array}{l}
\Psi_{\alpha-1}(t) \\
\Psi_{\beta-1}(t)
\end{array}\right]=\left[\begin{array}{l}
\Psi_{1} \cdot \sin \left(\omega_{1} \cdot t+\theta_{1}\right) \\
\Psi_{1} \cdot \cos \left(\omega_{1} \cdot t+\theta_{1}\right)
\end{array}\right]+\left[\begin{array}{l}
A_{0} \\
B_{0}
\end{array}\right]+Z
$$

with

$$
Z=\sum_{n=2}^{\infty}\left[\begin{array}{l}
\Psi_{n} \cdot \sin \left(\omega_{n} \cdot t+\theta_{n}\right) \\
\Psi_{n} \cdot \cos \left(\omega_{n} \cdot t+\theta_{n}\right)
\end{array}\right],
$$

where $\Psi_{n}$ is the magnitude of the $n^{\text {th }}$ term; $\omega_{n}$ its pulsation; $\theta_{n}$ its initial phase; $A_{0}$ and $B_{0}$ are, respectively, the DC offsets of $\Psi_{\alpha-i}$ and $\Psi_{\beta-i}$; $\Psi_{1}$ is the magnitude of fundamental components of the $\Psi_{\alpha i}$ and $\Psi_{\beta i}$. follows:

While the fundamental VF value is expressed as

$$
\left[\begin{array}{l}
\Psi_{\alpha}(t) \\
\Psi_{\beta}(t)
\end{array}\right]=\left[\begin{array}{l}
\Psi_{1} \cdot \sin \left(\omega_{1} \cdot t+\theta_{1}\right) \\
\Psi_{1} \cdot \cos \left(\omega_{1} \cdot t+\theta_{1}\right)
\end{array}\right]
$$

where $\Psi_{1}, \omega_{1}$ and $\theta_{1}$ is the magnitude components, pulsation and initial phase of fundamental.

Based on the grid voltage (13), the GVM inputs can be represented as follows:

$$
\left[\begin{array}{l}
U_{P} \\
U_{Q}
\end{array}\right]=\Psi_{g}\left[\begin{array}{cc}
\sin \left(\omega \cdot t+\theta_{1}\right) & -\cos \left(\omega \cdot t+\theta_{1}\right) \\
\cos \left(\omega \cdot t+\theta_{1}\right) & \sin \left(\omega \cdot t+\theta_{1}\right)
\end{array}\right]\left[\begin{array}{c}
\Psi_{\alpha} \\
\Psi_{\beta}
\end{array}\right] .
$$

The original control inputs can be calculated as follows:

$$
\left\{\begin{array}{l}
U_{\alpha}=\frac{\Psi_{\alpha} \cdot U_{P}-\Psi_{\beta} \cdot U_{Q}}{\Psi_{g}^{2}} ; \\
U_{\beta}=\frac{\Psi_{\beta} \cdot U_{P}-\Psi_{\alpha} \cdot U_{Q}}{\Psi_{g}^{2}} .
\end{array}\right.
$$

Figure 5 shows the block diagram of the proposed method.

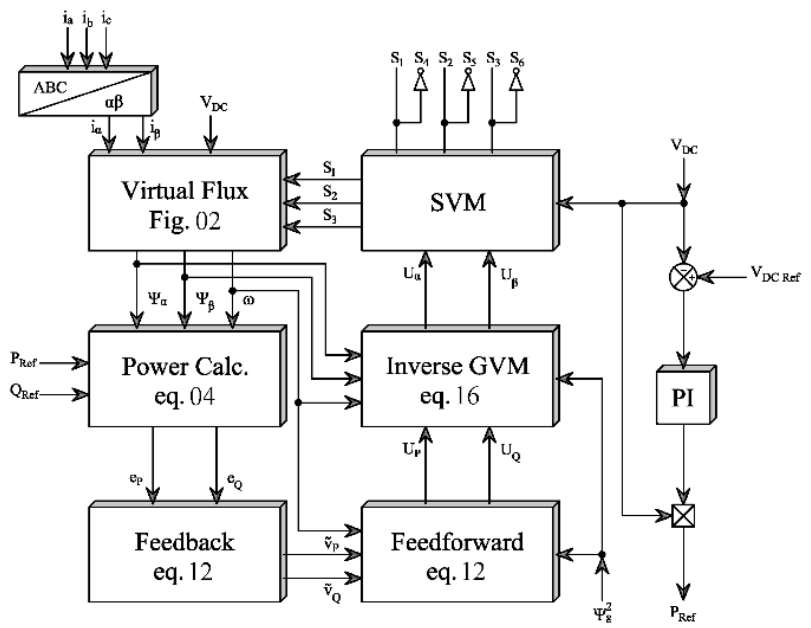

Fig. 5. Structure of VF-GVM-DPC controller

3. Simulation results. In order to provide a complete comparison work, the classical control and the proposed method are exposed to disturbed voltages which are implemented with the help of MATLAB / Simulink software. In a first step, a voltage unbalance and injection of the $7^{\text {th }}$ order harmonic are created and included in phase A at a cost of $20 \%$. Then, harmonics 5 and 7 with an amplitude of $20 \%$ is applied. A voltage unbalance of $20 \%$ and a $5^{\text {th }}$ order harmonic of $20 \%$ are created and included in phase A. Finally, which is the worst case that can occur with mains voltages, an asymmetrical disturbance with harmonics 5 and 7 with an amplitude of $20 \%$ is applied. We define the power fluctuation and the total harmonic distortion (THD) factor of input current as comparative criteria to demonstrate the superiority of the proposed strategy using simulation results. During all simulations, the $Q_{r e f}$ is kept at zero to ensure the functioning of the Unit Power Factor, which is an indispensable criterion.

The two compared methods are simulated under conditions shown in Fig. 6.

The following simulation results are obtained using the values of the parameters given in Table 2. 

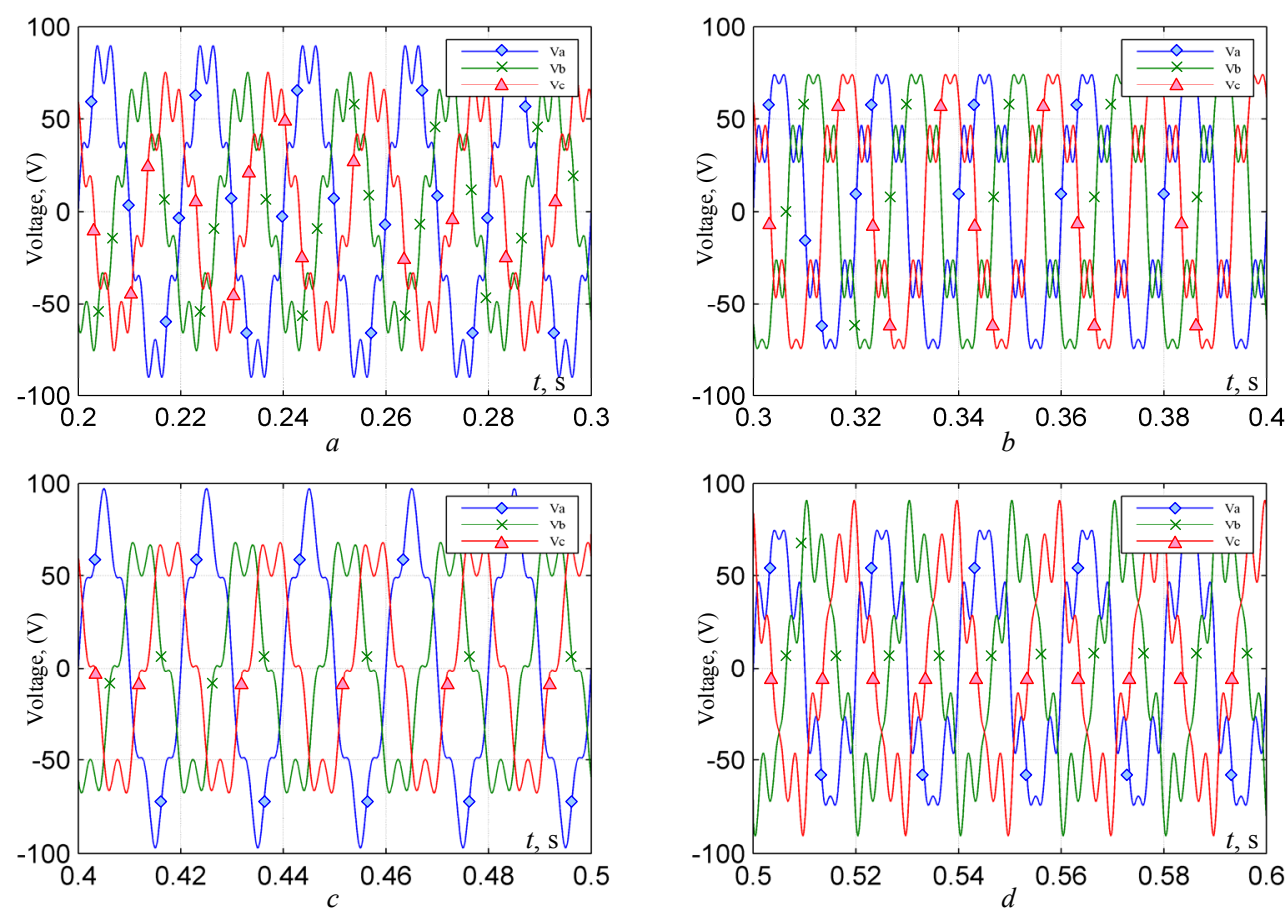

Fig. 6 . The different voltage source condition applied to the rectifier:

(a) - unbalanced and harmonic 7 to $20 \%$; (b) - harmonic 5 and 7 to $20 \%$;

(c) - unbalanced and harmonic 5 to $20 \%$; (d) - harmonic 5 and 7 to $20 \%$ asymmetric;

Table 2

System parameters used in simulation

\begin{tabular}{|l|c|c|l|c|c|c|c|c|}
\hline \multicolumn{1}{|c|}{ Parameters } & Symbol & Values & \multicolumn{1}{c|}{ Parameters } & Symbol & Values & Parameters & Symbol & Values \\
\hline The resistance of reactors & $\mathrm{R}$ & $0.56 \Omega$ & DC-bus capacitor & $\mathrm{C}$ & $1100 \mu \mathrm{F}$ & Switching frequency & $\mathrm{F}_{\mathrm{sw}}$ & $7500 \mathrm{~Hz}$ \\
\hline Load resistance & $\mathrm{RL}$ & $68.6 \Omega$ & The line-to-line AC voltage & $\mathrm{E}$ & $85 \mathrm{~V}$ & DC-bus voltage & VDC & $180 \mathrm{~V}$ \\
\hline Inductance of reactors & $\mathrm{L}$ & $19.5 \mathrm{mH}$ & Frequency & $\mathrm{F}$ & $50 \mathrm{~Hz}$ & Sampling period & $\mathrm{T}_{\mathrm{S}}$ & $20 \mu \mathrm{s}$ \\
\hline
\end{tabular}

Figure 7 shows the results for GVM-DPC:

- $(a)$ - the bus voltage curve;

- $(b)$ - the grid current;

- (c) - the estimated voltages $U_{\alpha \beta}$;

- $(d)$ - the superimposition current $i$ and voltage $V$ in phase A;

- $(e)$ - the active $P$ and reactive $Q$ powers.
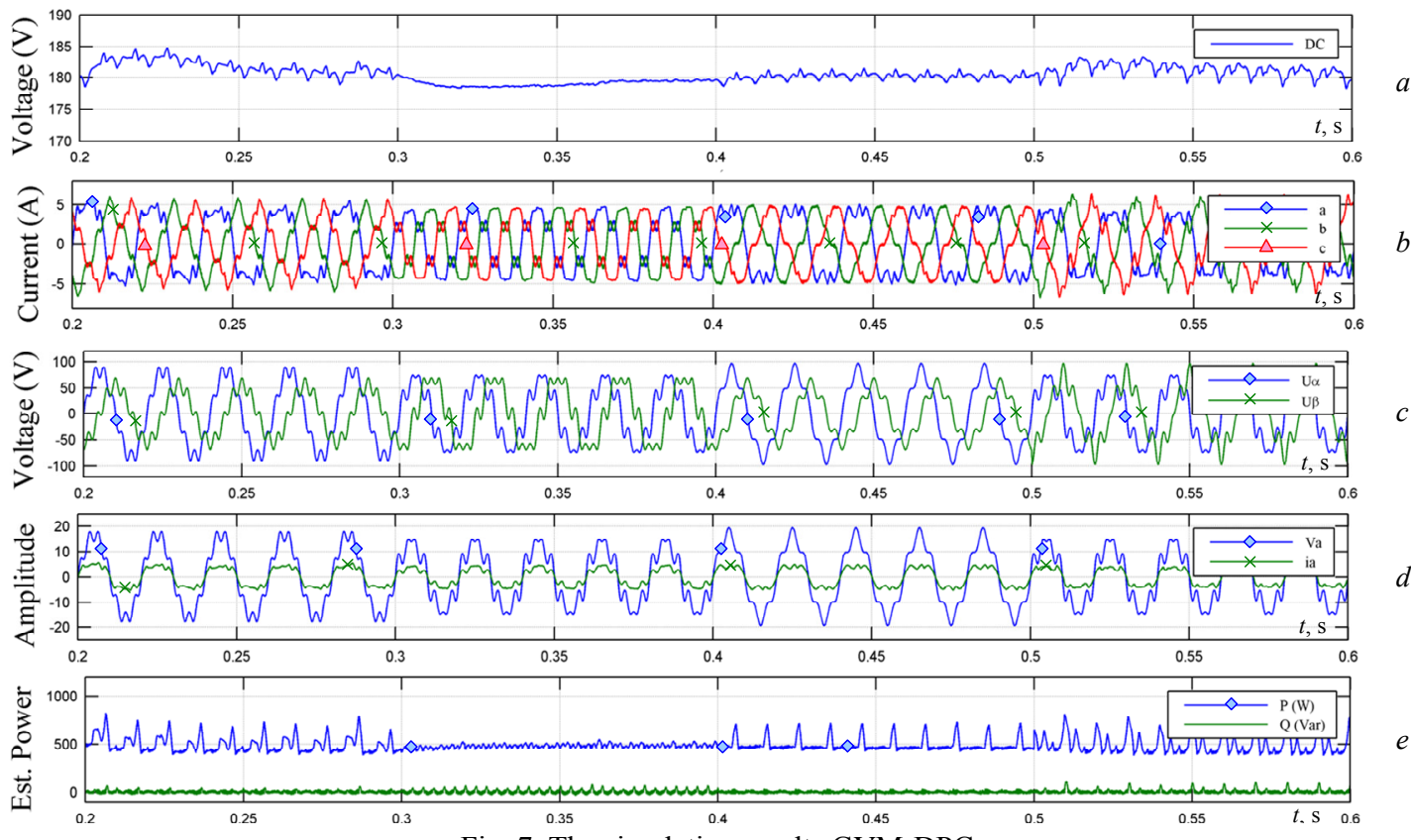

Fig. 7. The simulation results GVM-DPC

Figure 8 shows the results for VF-GVM-DPC:

- $(a)$ - the bus voltage curve;

- (b) - the grid current;

- $(c)$ - the estimated virtual flux $\Psi_{\alpha \beta}$;
- $(d)$ - the superposition current $i$ and the voltage $V$ in phase A;

- $(e)$ - the active $P$ and reactive $Q$ powers. 

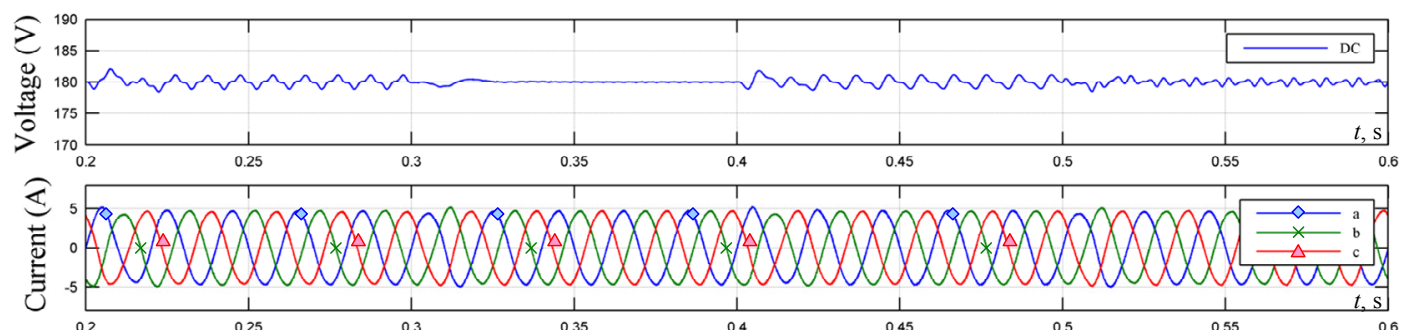

.
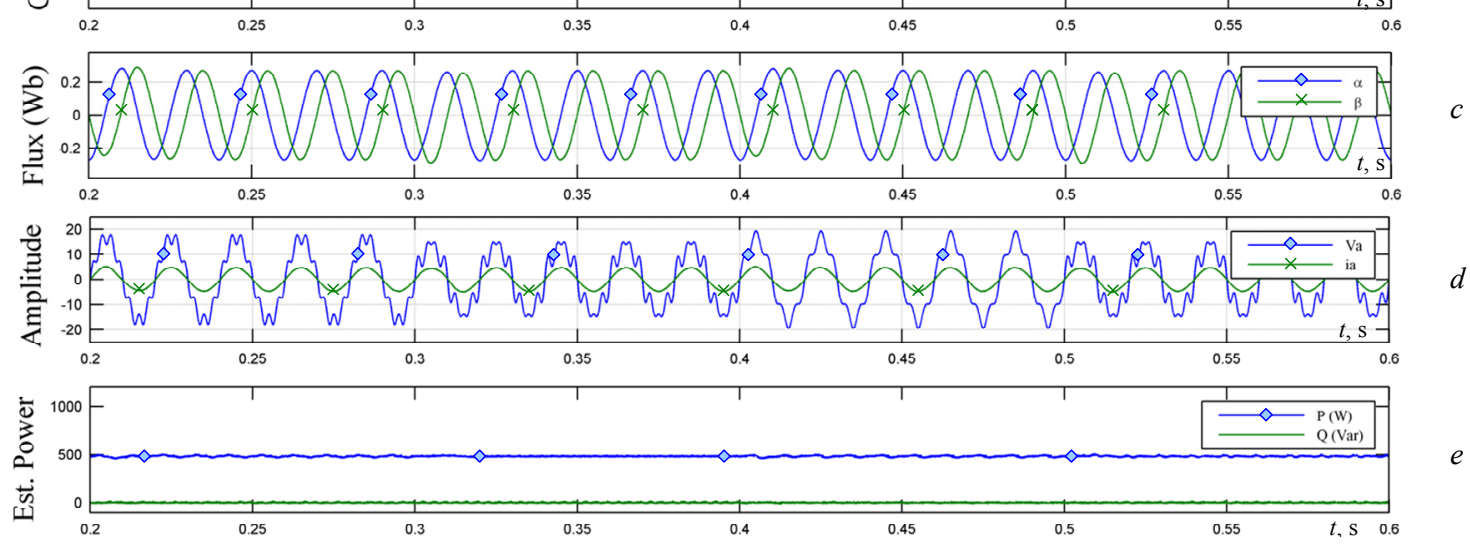

Fig. 8. The simulation result VF-GVM-DPC

The distribution of Fig. 7 is the same as that of Fig. 8. We can see in Fig. 7 the GVM-DPC which leads to fluctuations in the voltage curve of the bus. In addition, the grid current is affected by disturbed grid voltage conditions, with a high THD rate, which reduces the accuracy of the estimates of active and reactive power as can be seen in Fig. 7. In addition, the DC bus seriously oscillates around $5 \mathrm{~V}$ and the system does not operate under a unit power factor which is a very important criterion during our comparison.

On the other hand, we can see in Fig. 8 VF-GVMDPC which gives us the current and the voltage are in phase. Although there are still some low order harmonics, we can observe that they have a limited influence compared to that of Fig. 7. The oscillations of the vector component of the estimated flux are sinusoidal and out of phase without disturbance and fluctuation.

Figure 9 shows the bus voltage stabilizers at about minus $2 \mathrm{~V}$ and the system is operating at unity power factor.
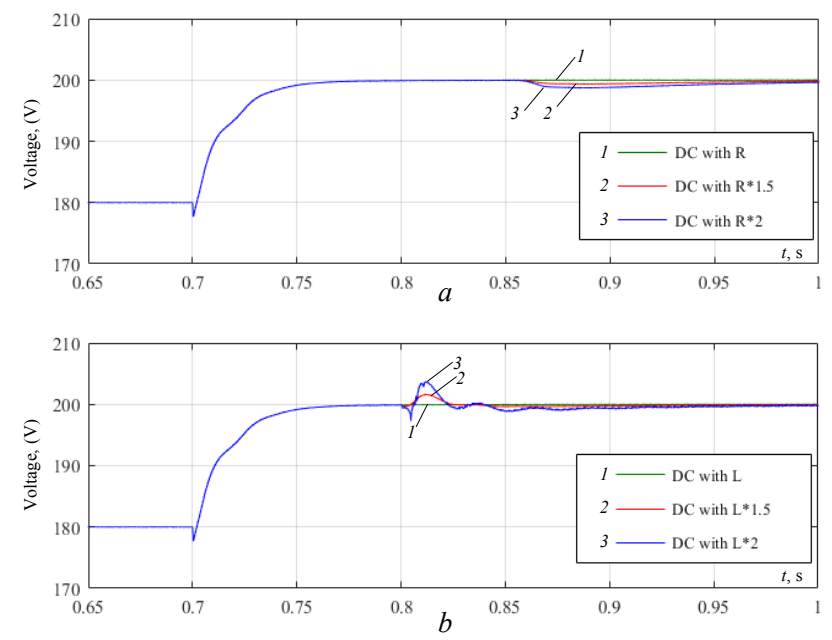

Fig. 9. System parameters influence on the evolution of the DC bus voltage: $\mathrm{R}(a)$; L (b)
Figure 10 shows the difference between the application of an SRF-PLL and a PLL which operates on the basis of a fuzzy logic controller to detect the fundamental frequency positive sequence component of the mains voltage in unbalanced and distorted conditions as well as fast and smooth tracking.

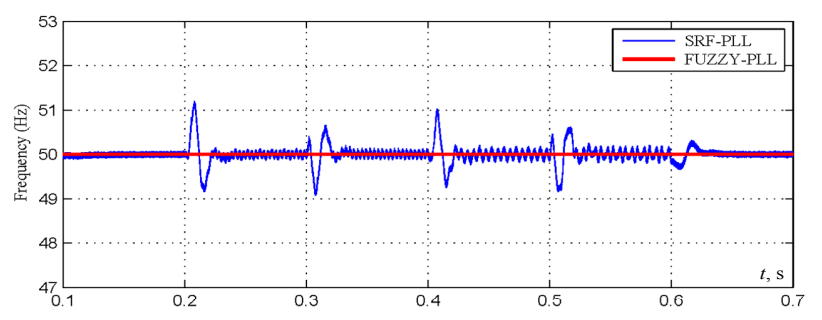

Fig. 10. The difference between Synchronous Reference Frame based Phase Locked Loop and proposed fuzzy-PLL

From Fig. 11 we can note that the THD rate of the network current has been improved compared to traditional control while respecting the standard of the electrical network. To highlight the contribution of the oscillatory terms, first of all, the results of the proposed control structure are shown in Fig. 2. The design and optimization process were carried out in the same manner as the procedure presented above. This result expressly shows how the components of the low order harmonics (5 and 7) with symmetrical and asymmetrical fault of the network voltage affect the network current. To summarize the results, Fig. 11 below presents an analysis based on the current THD of the VF-GVM-DPC strategies studied in this article. 

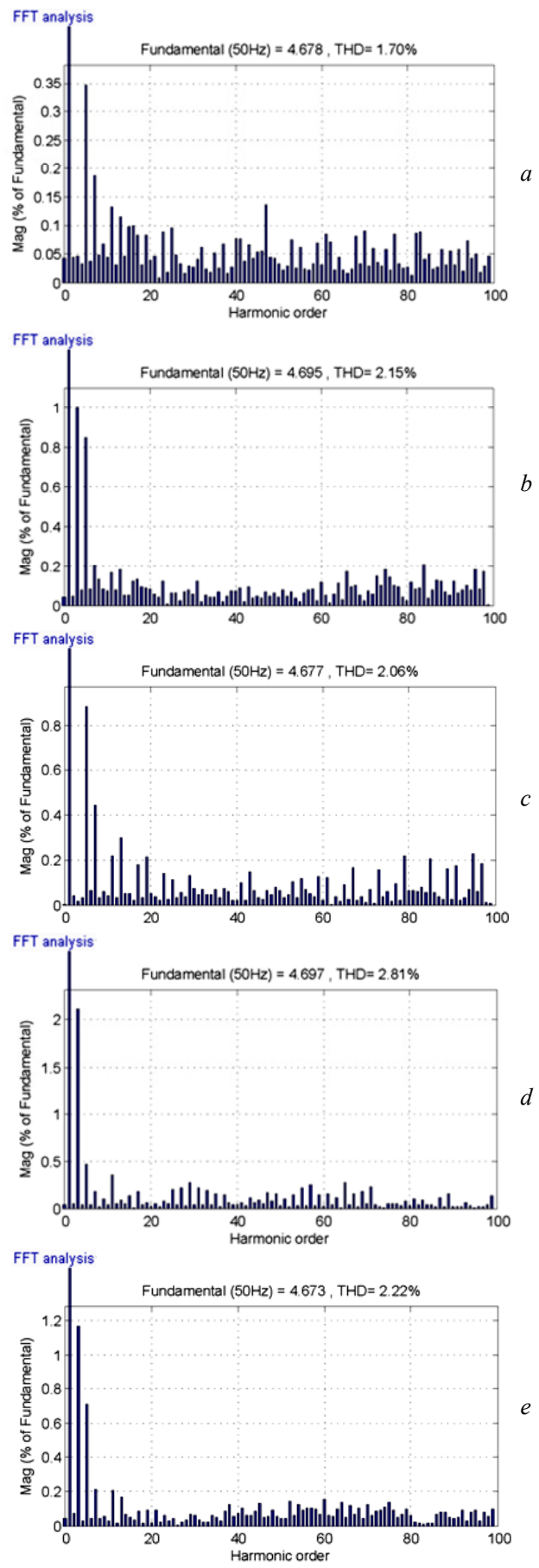

Fig. 11. Fast Fourier Transform analysis showing THD in source current of the proposed method:

a) ideal network voltage conditions;

b) unbalance and injection of the 7th order harmonic;

c) injection harmonics 5 and 7 ;

d) an asymmetrical disturbance with harmonics 5;

$e)$ an asymmetrical disturbance with harmonics 5 and 7

\section{Conclusions.}

This paper presented the mathematical analysis and the numerical implementation of an improved method of Grid Voltage Modulated based on Direct Power Control or we introduced them for three phase rectifiers. The main objectives of the proposed control strategy are to obtain sinusoidal input currents under different input voltage conditions and to maintain the DC bus voltage at the level required as part of the improvement of the wind chain.
In these situations, harmonic components appear on the grid voltage, which causes distortion and current imbalance if the power reference is kept constant. However, the use of the proposed Virtual Flux-Grid Voltage Modulated method has the same control structure as the classic Grid Voltage Modulated, except for the use of virtual flux instead of voltages, which results in the optimization of the cost, since the voltage sensors will not be used, which is based on the principle of disturbance rejection, makes it possible to obtain an input current of low THD compared to the conventional method.

The proposed control method could offer many advantages and allows to obtain good performances with a THD of $1.7 \%$ under ideal conditions and during disturbances it varies between $2.06 \%$ to $2.81 \%$ which respects the standard, without forgetting with a load lower calculation, without it being necessary to specify the power calculation term, nor to extract the positive / negative voltage sequence. We can therefore say that this control method is able to improve the quality of the input current.

Conflict of interest. The authors declare that they have no conflicts of interest.

\section{REFERENCES}

1. Bayoumi E.H.E. Power electronics in smart grid power transmission systems: a review. International Journal of Industrial Electronics and Drives, 2015, vol. 2, no. 2, p. 98. doi: https://doi.org/10.1504/ijied.2015.069784.

2. Akagi H., Watanabe E.H., Aredes M. The Instantaneous Power Theory. In Instantaneous Power Theory and Applications to Power Conditioning (eds H. Akagi, E.H. Watanabe and M. Aredes). 2017. doi: https://doi.org/10.1002/9780470118931.ch3. 3. Depenbrock M. Direct self-control of the flux and rotary moment of a rotary-field machine. US Patent no. 4678248A, Jul. 07 , $1987 . \quad$ Available at: https://patentimages.storage.googleapis.com/89/13/c0/9d04c66 7c8003f/US4678248.pdf (accessed 14 March 2021).

4. Yousefi-Talouki A., Zalzar S., Pouresmaeil E. Direct Power Control of Matrix Converter-Fed DFIG with Fixed Switching Frequency. Sustainability, 2019, vol. 11, no. 9, p. 2604. doi: https://doi.org/10.3390/su11092604.

5. Berkani A., Bey M., Araria R., Allaoui T. A new approach based on Fuzzy-Q-Learning algorithm to control 3 level T-type voltage source converter. Journal Européen des Systèmes Automatisés, 2020, vol. 53, no. 6, pp. 845-852. doi: https://doi.org/10.18280/jesa.530610.

6. Chaoui A., Gaubert J.-P., Krim F. Power quality improvement using DPC controlled three-phase shunt active filter. Electric Power Systems Research, 2010, vol. 80, no. 6, pp. 657-666. doi: https://doi.org/10.1016/j.epsr.2009.10.020.

7. Laggoun Z.E.Z., Khalile N., Benalla H. A Comparative study between DPC-SVM and PDPC-SVM. 2019 International Conference on Advanced Electrical Engineering (ICAEE), 2019, pp. 1-5. doi: https://doi.org/10.1109/ICAEE47123.2019.9014796. 8. Malinowski M., Jasinski M., Kazmierkowski M.P. Simple direct power control of three-phase PWM rectifier using spacevector modulation (DPC-SVM). IEEE Transactions on Industrial Electronics, 2004, vol. 51, no. 2, pp. 447-454. doi: https://doi.org/10.1109/TIE.2004.825278.

9. Shang L., Hu J. Sliding-Mode-Based Direct Power Control of Grid-Connected Wind-Turbine-Driven Doubly Fed Induction Generators Under Unbalanced Grid Voltage Conditions. IEEE Transactions on Energy Conversion, 2012, vol. 27, no. 2, pp. 362-373. doi: https://doi.org/10.1109/TEC.2011.2180389.

10. Wai R., Yang Y. Design of Backstepping Direct Power Control for Three-Phase PWM Rectifier. IEEE Transactions on 
Industry Applications, 2019, vol. 55, no. 3, pp. 3160-3173. doi: https://doi.org/10.1109/TIA.2019.2893832.

11. Bouafia A., Gaubert J., Krim F. Predictive Direct Power Control of Three-Phase Pulsewidth Modulation (PWM) Rectifier Using Space-Vector Modulation (SVM). IEEE Transactions on Power Electronics, 2010, vol. 25, no. 1, pp. 228-236. doi: https://doi.org/10.1109/TPEL.2009.2028731.

12. Norniella J.G., Cano J.M., Orcajo G.A., Rojas C.H., Pedrayes J.F., Cabanas M.F., Melero M.G. Multiple switching tables direct power control of active front-end rectifiers. IET Power Electronics, 2014, vol. 7, no. 6, pp. 1578-1589. doi: https://doi.org/10.1049/iet-pel.2013.0492.

13. Tao Y., Wu Q., Wang L., Tang W. Voltage sensorless predictive direct power control of three-phase PWM converters. IET Power Electronics, 2016, vol. 9, no. 5, pp. 1009-1018. doi https://doi.org/10.1049/iet-pel.2014.0713.

14. Suul J.A., Luna A., Rodríguez P., Undeland T. VirtualFlux-Based Voltage-Sensor-Less Power Control for Unbalanced Grid Conditions. IEEE Transactions on Power Electronics, 2012, vol. 27, no. 9, pp. 4071-4087. doi: https://doi.org/10.1109/TPEL.2012.2190301.

15. Ketzer M.B., Jacobina C.B. Virtual Flux Sensorless Control for Shunt Active Power Filters With Quasi-Resonant Compensators. IEEE Transactions on Power Electronics, 2016, vol. 31, no. 7, pp. 4818-4830. doi: https://doi.org/10.1109/TPEL.2015.2487298.
16. Laggoun Z.E.Z., Benalla H., Nebti K. Dual Virtual Fluxbased Direct Power Control for rectifier under harmonically distorted voltage condition. Archives of Electrical Engineering, 2020, vol. 69, no. 4, pp. 951-966. doi: https://doi.org/10.24425/aee.2020.134641.

17. Gui Y., Kim C., Chung C.C., Guerrero J.M., Guan Y., Vasquez J.C. Improved Direct Power Control for GridConnected Voltage Source Converters. IEEE Transactions on Industrial Electronics, 2018, vol. 65, no. 10, pp. 8041-8051. doi: https://doi.org/10.1109/TIE.2018.2801835.

Received 15.10.2021

Accepted 18.11.2021

Published 03.12.2021

Zakaria El Zair Laggoun ${ }^{1}$, PhD Student,

Hocine Benalla ${ }^{1}$, Doctor of Electrical Engineering, Professor,

Khalil Nebti ${ }^{1}, P h D, M C A$,

${ }^{1}$ Laboratory of Electrotechnics of Constantine (LEC),

Mentouri Brothers University, Constantine 1,

Campus Ahmed Hamani Zerzara,

Route d'Ain el Bey, Constantine, 25000, Algeria,

e-mail:

zakaria-el-zair.laggoun@lec-umc.org (Corresponding author),

benalladz@yahoo.fr,

idor2003@yahoo.fr

How to cite this article:

Laggoun Z.E.Z., Benalla H., Nebti K. A power quality enhanced for the wind turbine with sensorless direct power control under different input voltage conditions. Electrical Engineering \& Electromechanics, 2021, no. 6, pp. 64-71. doi: https://doi.org/10.20998/2074-272X.2021.6.09. 